\title{
PAISAGENS SONORAS: POSSÍVEIS CAMINHOS AOS ESTUDOS CULTURAIS EM GEOGRAFIA
}

\section{Soundscapes: possible ways to study in cultural geography}

\author{
Marcos Alberto Torres ${ }^{1}$ \\ Salete Kozel ${ }^{2}$
}

\begin{abstract}
RESUMO
Paisagem é um conceito de interesse da Geografia desde o seu surgimento enquanto ciência. Aplicada para representar uma unidade do espaço, um lugar, a paisagem - portadora de formas, cores, cheiros, barulhos e movimentos - imprime suas marcas na cultura ao passo que recebe suas marcas, numa relação dinâmica recíproca. Os estudos geográficos da paisagem e da cultura, especificamente na paisagem sonora, possível por meio de uma abordagem humanista-cultural, trazem à luz as preocupações com a compreensão de como o indivíduo e o coletivo constroem e concebem o espaço. No presente artigo, pretende-se discutir o conceito de paisagem na Geografia, e apontar caminhos para estudos que tenham por base a paisagem sonora, na busca da compreensão da cultura e do lugar.
\end{abstract}

Palavras-chave: Paisagem; paisagem sonora; música; percepção; memória.

\begin{abstract}
$^{3}$
Landscape as a concept is studied in Geography since its inception as a science. Landscape is used to represent a unit of space, a place - including its shapes, colors, smells, sounds and movements - marking the culture. In geography, the study of culture and landscape, taking soundscape as basis, within a humanistic and cultural approach, informs about the understanding of how both an individual and a community construct and conceive space. In this article the concept of landscape in Geography is discussed, trying to orientate paths that guide studies based on the search to understand culture and place.
\end{abstract}

Keywords: landscape; soundscape; music; perception; memory.

1 Mestre em Geografia pela Universidade Federal do Paraná. E-mail: torresmarcos@hotmail.com.

2 Professora adjunta do Departamento de Geografia da Universidade Federal do Paraná - UFPR. Doutora em Geografia pela USP. E-mail: skozel@ufpr.br.

3 Tradução para o inglês: Patrícia Talhari. 
TORRES, M. A.; KOZEL, S. Paisagens sonoras: possíveis caminhos aos estudos...

\section{BREVE INTRODUÇÃO SOBRE A PAISAGEM GEOGRÁFICA}

O conceito de paisagem à Geografia é aplicado para representar uma unidade do espaço, um lugar, e remete às percepções que se tem sobre ele. Cada paisagem é produto e produtora da cultura, e é possuidora de formas, cores, cheiros, sons e movimentos que podem ser experienciados por cada pessoa que se integra a ela, ou abstraído por aquele que a lê através de relatos e/ou imagens. Diante disso, o presente artigo pretende discutir o conceito de paisagem na Geografia, e apontar caminhos para estudos que tenham por base a paisagem sonora na busca da compreensão da cultura e do lugar.

No senso comum não é rara a atribuição do termo paisagem a um lugar tranquilo, na maioria das vezes sem a presença direta do ser humano, o que, para Salgueiro (2001), se deu pela relação estabelecida entre paisagem e pintura, na qual foi primeiramente utilizada para descrever uma representação pictórica do campo. Segundo a autora "o belo correspondia ao perfeito na pintura e as pessoas cultas procuravam observar as paisagens que eram conformes às normas fixadas na pintura" (SALGUEIRO, 2001, p. 38). Para a autora, no século XIX "os pintores continuaram a produzir paisagens bucólicas, ignorando totalmente as transformações que, entretanto, ocorriam no real" (SALGUEIRO, 2001, p. 39).

Jorge Gaspar, no entanto, ao discutir o surgimento do conceito de paisagem, apresenta a hipótese de que os viajantes podem ter antecedido o período renascentista no estímulo ao uso e definição da paisagem. (GASPAR, 2001, p. 85). À Geografia, interessa saber que a paisagem foi alvo de interesse dos geógrafos desde sua constituição como disciplina (CLAVAL, 2004, p. 16). As descrições das paisagens, que estiveram no cerne dos trabalhos dos viajantes que se utilizavam da geografia, foram dificultosas até o início do século XVIII pela falta de um vocabulário próprio para discorrer sobre as formas do relevo ou das rochas, e isso contribuiu para que os geógrafos passassem a ilustrar seus trabalhos com gravuras, como, por exemplo, o trabalho editado por Alexander Von Humboldt após suas viagens pela América Latina, sob o título Vues des Cordillères et Monuments des Peuples Indigènes de l'Amèrique, constituído de 69 pranchas comentadas, com uma seleção de paisagens, muitas delas em aquarela (CLAVAL, 2004, p. 16). Entretanto, o avanço das ciências foi responsável pela criação de um rico vocabulário científico, que contribuiu e contribui para as descrições e análises das diferentes paisagens que o mundo possui.
Nos estudos das paisagens na Geografia até o início dos anos 1970, o desenvolvimento científico permitiu que se tomasse consciência das relações entre os aspectos físicos, os componentes biológicos e as realidades nos ambientes sociais (CLAVAL, 2004, p. 47). Contudo, a preocupação com a objetividade, que estava presente nos primeiros trabalhos descritivos da paisagem, até então não havia sido superada, e somente no decorrer da década de 1970 modificaramse as atitudes dos geógrafos, face às contribuições da fenomenologia para o pensamento geográfico. Claval, ao referir-se sobre as posturas e as práticas dos geógrafos da década de 1970, constata que:

O impacto das filosofias fenomenológicas influenciouas significativamente: o mundo que o indivíduo percebe jamais é objetivamente dado. É preciso fazer um esforço para retornar às sensações e desconstruir aquilo que nossa educação nos ensinou; então, e só então, é possível, através de uma descrição crítica e minuciosa das sensações, compreender as coisas como elas são e penetrar na sua verdadeira natureza. [...] Não é este o momento de lembrar que a paisagem é criada pelo observador e que ela depende do ponto de vista que ele escolheu e do enquadramento que ele Ihe dá? A liberdade que tem o geógrafo de se deslocar para multiplicar os ângulos não elimina essa dimensão subjetiva. (CLAVAL, 2004, p. 48).

Claval cita ainda Roger Brunet, que afirma que a paisagem "só é paisagem quando percebida" (CLAVAL, 2004, p. 48). Entendendo que a percepção não limita-se ao sentido da visão, o estudo da paisagem na Geografia deve ir além dos aspectos visuais, e isso pressupõe considerar sua dimensão subjetiva. A paisagem é um complexo de formas e relações culturais, e à Geografia cabe a busca da compreensão de cada paisagem, não só pela aparência numa leitura estética, mas na busca de desvendar os significados dos lugares e as relações neles e entre eles estabelecidas.

Cada paisagem traz em si valores erigidos no decorrer do tempo. Uma pessoa que vive muitos anos numa mesma casa, cria laços afetivos com o lugar e com os moradores vizinhos. Para Tuan, "uma pessoa no transcurso do tempo, investe parte de sua vida emocional em seu lar e além do lar, em seu bairro". (TUAN, 1980, p. 114). Essa afetividade é expressa na paisagem tanto nas formas físicas (casas, cores, jardins, etc.), como também nas relações e significados presentes na paisagem, o que comprova uma dinâmica constante existente: a paisagem percebida não será mais a mesma num momento posterior, mas manterá elementos dos quais foram percebidos anteriormente, enquanto outros já terão sido alterados. Para Almeida, "a paisagem é 
TORRES, M. A.; KOZEL, S. Paisagens sonoras: possíveis caminhos aos estudos...

uma complexidade multiforme de realidades, de valores, de gestos e de vividos coexistentes" (ALMEIDA, 2003, p. 86). Ao mesmo tempo em que apresenta elementos da(s) vida(s) que a habita, é refletida por cada vida que nela há.

Cada cultura, segundo os valores nela construídos no decorrer do tempo, apropria-se da natureza e dos elementos presentes no meio onde habita e transforma-os, o que é expresso na paisagem. Ao refletir uma cultura, a paisagem deve ser entendida como um receptáculo de símbolos. Para Cosgrove (2004, p. 108), "todas as paisagens possuem significados simbólicos porque são o produto da apropriação e transformação do meio ambiente pelo homem".

Berque (2004, p. 86) explica ainda que a paisagem é plurimodal (passiva-ativa-potencial etc.) como é plurimodal o sujeito para o qual a paisagem existe. Explica também que paisagem e sujeito são cointegrados em um conjunto unitário, que se autoproduz e se autorreproduz. Nesse sentido, fica claro que a análise da paisagem não deve valer-se apenas do aspecto visual, pois a visão não é suficiente para captar e explicar todos os elementos físicos e simbólicos presentes na paisagem.

De fato, o que está em causa não é somente a visão, mas todos os sentidos; não somente a percepção, mas todos os modos de relação do indivíduo com o mundo; enfim, não é somente o indivíduo, mas tudo aquilo pelo qual a sociedade o condiciona e o supera, isto é, ela situa os indivíduos no seio de uma cultura, dando com isso um sentido à sua relação com o mundo (sentido que, naturalmente, nunca é exatamente o mesmo para cada indivíduo). (BERQUE, 2004, p. 87).

Diante disso, os demais elementos de uma paisagem ganham foco: os sons, os cheiros, as formas e os movimentos, assim como os símbolos e significados presentes na paisagem. Nos capítulos que seguem, o conceito de paisagem será aprofundado por meio de reflexões acerca dos trabalhos de geógrafos que buscaram explicar a paisagem por meio de elementos não visuais, como os cheiros e os sons, e apontar caminhos para estudos que tenham por base a paisagem sonora, na busca da compreensão da cultura e do lugar.

\section{A PAISAGEM ALÉM DO VISUAL}

Todo som (falas, ruídos, músicas, etc.) e todo cheiro (perfumes, plantas, esgotos, etc.) têm uma origem que está diretamente relacionada ao lugar. Nossas percepções e nossos olhares perpassam nossas expe- riências e vivências em diferentes tipos de espaços.

Ao referir-se aos cheiros presentes na paisagem, Gaspar explica que "embora menos consciencializada que outras paisagens, a olfativa deixa impressões fortes na memória dos lugares e dos monumentos" (GASPAR, 2001, p. 89). No seu trabalho, Gaspar cita exemplos de oposição de paisagens olfativas existentes na Península Ibérica, e retoma o precursor trabalho de Porteous, no Canadá, que cunhou o termo smellscape em suas pesquisas acerca das paisagens olfativas. Gaspar (2001), no intuito de apresentar o estudo da paisagem em diferentes especificidades, ainda discorre sobre experimentos que fez acerca das paisagens táteis e das paisagens biográficas, e faz ainda uma breve discussão acerca das paisagens sonoras e sua pertinência para os estudos geográficos. Em sua reflexão sobre a paisagem sonora, relata a experiência com paisagens sonoras distintas, o que comprova que a paisagem sonora é responsável por também conceder identidade ao lugar.

As paisagens sonoras, apesar de exploradas por musicólogos, antropólogos e etnomusicólogos, apresentam-se à Geografia como importante campo de estudo. Assim como a olfativa, a paisagem sonora é marcante para a lembrança de um lugar, concordando com Stanley Waterman (2006, p. 01), que afirma que os sentidos da audição e do olfato são capazes de evocar memórias e imagens mais poderosas do que as coisas que vemos, e seus usos seletivos permitem a produção de imagens mais robustas. Para este autor, os olhos fazem a varredura e captam o cenário mais amplo rapidamente, mas os sentidos da audição e do olfato reagem mais lentamente e talvez mais profundamente.

As paisagens sonoras concedem identidades aos lugares, e agem direta e constantemente em seus moradores na contribuição à perpetuação das falas e sotaques, dos gostos musicais, e na evocação de paisagens do passado, o que reforça valores existentes em cada indivíduo, que pode contribuir para sua fixação em lugares distintos, e à criação do sentimento de pertencimento a eles, pelo fato de apresentarem sonoridades que concedem familiaridade na paisagem.

\section{OS LUGARES E OS SONS: A PAISAGEM SONORA}

Diferentes sons ocupam os lugares, de diferentes maneiras e assumindo diferentes formas. Nas cidades, os sons dos veículos automotores, das pessoas caminhando e/ou conversando, das propagandas comerciais, dos aparelhos eletroeletrônicos, das manifestações religiosas, da construção civil, entre outros, compõem o universo sonoro. Em comunidades rurais, os sons que 
TORRES, M. A.; KOZEL, S. Paisagens sonoras: possíveis caminhos aos estudos...

compõem suas paisagens sonoras são outros, uma vez que os sons produzidos pelo homem e suas técnicas aparecem em menor intensidade que na cidade, proporcionando que os sons da natureza - como o canto dos pássaros ou os sons dos rios e do vento - sejam mais perceptíveis. Da mesma forma, a cultura presente nesses lugares marca a paisagem diferentemente do meio urbano.

De acordo com Wisnik, o som é onda, os corpos vibram, e essas vibrações transmitem-se sob formas de propagações ondulatórias, capazes de serem captadas pelos nossos ouvidos, e interpretadas pelo cérebro, o que lhes dá configurações e sentidos (WISNIK, 1989, p. 17). Desse modo, as ondas sonoras estão presentes no espaço, ocupando-o e agindo sobre os seres humanos. Contudo, o estudo dos sons presentes no espaço deve considerar as transformações que ocorreram e ocorrem em diferentes lugares.

Fatos históricos determinaram mudanças no ritmo de vida da humanidade, marcando também alterações na organização do espaço. O homem move-se no ritmo do meio, do espaço onde vive. As grandes navegações do século $\mathrm{XVI}$, a revolução industrial, o surgimento da energia elétrica, e a revolução tecno-científica, são eventos que marcaram a história determinando novos ritmos de vida às populações.

Para Tuan o mundo é percebido pelo ser humano simultaneamente através de todos os sentidos, sendo imensa a informação potencialmente disponível. No entanto, no dia a dia do homem, é utilizada somente uma pequena porção do seu poder inato para experienciar (TUAN, 1980, p. 12). Durante uma gestação, no ventre materno, o bebê que é gerado recebe do mundo externo os primeiros estímulos através dos sons. Enquanto a visão, o tato e o paladar são impossíveis de serem utilizados no contato com o mundo externo, os sons deste mundo desconhecido já atingem o bebê, apresentando-lhe vozes de pessoas com quem vai passar grande parte de sua vida, e dos demais eventos sonoros que as paisagens sonoras the proporcionarem. Com isso, pode-se afirmar que o primeiro contato de um ser humano com o mundo surge pelo sentido da audição, e isso faz com que esse sentido aja em cada criança, configurando um mundo menos desconhecido e mais seguro ao reconhecer as vozes que ouve desde que estava no ventre materno. O sentido da audição, dessa forma, é um sentido que age profundamente, desde o nascimento, na vida dos seres humanos, e que configura um mundo novo e desconhecido pelos sons que ainda não ouviu, ou um mundo mais seguro através dos sons que reconhece.
No meio urbano, a quantidade de sons que compõem a paisagem sonora acaba por tornar confusas muitas das informações nela contidas. No livro Kaleidosfone, onde Nelson Aprobato Filho publicou seus estudos sobre a paisagem sonora da cidade de São Paulo do final do século XIX até o início do século $\mathrm{XX}$, o autor relata:

Viver em São Paulo é renunciar ao silêncio, é incorporar-se, voluntária ou involuntariamente, a ritmos desencontrados, fragmentados por ruídos irritantes, harmonias inusitadas e dissonâncias estonteantes. As reclamações e denúncias contra a atual poluição sonora tornam-se constantes. As tentativas e medidas criadas para a sua contenção mostram-se raras e ineficazes. Quando existem, são freqüentemente desrespeitadas e, de quando em quando, os meios de comunicação de massa trazem essa questão à tona. (APROBATO FILHO, 2008, p. 28).

O que é relatado por Aprobato Filho evidenciase nas demais cidades brasileiras, o que certamente aparecerá em maior proporção nas grandes cidades, mas que não isenta as pequenas e médias cidades da constatação do fato da superprodução dos sons. Nas ruas, a variedade de barulhos advindos dos motores dos carros, caminhões e motocicletas, as buzinas, os apitos dos guardas de trânsito, as pessoas caminhando, as falas, as propagandas comerciais nas lojas, os pregões dos vendedores ambulantes, os sinos das igrejas, as músicas reproduzidas em alto-falantes nos estabelecimentos comerciais ou nos carros de jovens que gostam de ouvir música alta, são exemplos da infinidade de sons que um centro urbano revela, e que podem vir a encobrir o som da voz de uma pessoa a nos chamar pelo nome, o que evidencia a superprodução de sons do meio urbano, que tende a tornar sua paisagem sonora confusa. O início do fenômeno da superprodução de sons no meio urbano tem como marco a Revolução Industrial.

A Revolução Industrial marcou uma nova fase na história da humanidade, não apenas pelas transformações espaciais por ela desencadeadas, como o êxodo rural ou o modo de vida urbano que se intensifica e expande a cada dia, mas também pela gama de sons que surgiram, primeiramente, com as máquinas movidas a carvão ou vapor. Com a descoberta de novas fontes de energia, como o petróleo e a eletricidade, o mundo presenciou um novo marco nas transformações espaciais, e no que diz respeito à paisagem sonora, a proliferação e amplificação dos sons tornou-se evidente, através dos veículos automotores, do uso dos amplificadores 
TORRES, M. A.; KOZEL, S. Paisagens sonoras: possíveis caminhos aos estudos...

elétricos e dos diferentes meios de acondicionamento de som - gravadores - capazes de reproduzi-los a qualquer instante, em qualquer lugar e em qualquer volume (SCHAFER, 2001, p. 107).

O mundo contemporâneo presencia, assim, uma infinidade de novos sons que diferem em qualidade e intensidade. Esses novos sons fundem-se aos historicamente já existentes, superpovoando o meio.

Em diferentes lugares, a paisagem sonora apresenta-se com inúmeras informações, sejam elas urbanas e tecnificadas, ou de um ambiente natural ou próximo disso. Entretanto, a paisagem sonora é pouco percebida, assim como as transformações que nela ocorrem.

Por comportar todos os sons de um determinado lugar, a paisagem sonora pode conter sons de diferentes naturezas, como por exemplo:

- Os sons dos animais;

- Os sons dos fenômenos da natureza (vento, chuva, trovões, mar, etc.);

- Os sons advindos dos objetos construídos pelos seres humanos (meios de transporte, ferramentas de trabalho, aparelhos eletrodomésticos, etc.);

- Os sons dos seres humanos (falas, sotaques, ato de caminhar ou correr, as músicas, etc.); entre outros.

A paisagem sonora é cultural, pois reflete a identidade de um lugar e de seus habitantes. Os sons do trânsito possuem, além dos sons dos motores, códigos que são específicos em cada grupo social. As buzinas das motocicletas e automóveis podem ser sons agressivos em uma localidade, enquanto em outra é encarado de maneira natural. Sons da construção civil podem ser tolerados até tarde da noite em algumas localidades, enquanto em outras são estabelecidas leis ou critérios para que não ultrapassem os horários comerciais. Uma festa pode durar uma noite inteira em certos lugares, ao som de músicas em alto volume, conversas e risadas, enquanto em outros existem limites de decibéis e/ou horários estabelecidos para que as festas aconteçam. Assim, cada lugar apresenta especificidades na paisagem sonora.

É na paisagem sonora ainda que encontramos subsídios para pensar na perpetuação das diferentes falas e sotaques dos grupos sociais, e no estabelecimento da comunicação entre seus integrantes. A comunicação estabelecida pela fala encontra na paisagem sonora os primeiros elementos para a construção da linguagem, que implica em conteúdo e expressão. Para Ernst Cas- sirer (2001, p. 175),

ambos, o conteúdo e a expressão, somente se tornam o que são na sua interpenetração recíproca: a significação que adquire nesta correlação não se acrescenta apenas exteriormente ao seu ser, posto que é a significação que constitui esse ser.

Assim podemos aferir que a linguagem - um dos elementos que compõem o universo simbólico do pensamento Cassireriano, ao lado da religião, do mito e da arte (CASSIRER, 1994) -, está presente na paisagem sonora por meio da fala e de suas imbricações com a cultura, pois por meio da fala torna-se possível a comunicação, expressão, significação e, assim, a construção e perpetuação de valores de um grupo. Para Cassirer, o princípio da linguagem, assim como da arte, é a imitação, e sua principal função nesse quesito é mimética. "A linguagem é uma imitação de sons, a arte é uma imitação de coisas externas" (CASSIRER, 1994, p. 227). Contudo, Cassirer chama atenção para o fato de que a linguagem e a arte oscilam constantemente entre dois polos opostos, um objetivo e outro subjetivo. Do mesmo modo que a fala, a música integra a paisagem sonora, e, enquanto expressão artística, também compõe o universo simbólico de um povo. Deverá ser estudada, sobretudo, no aspecto subjetivo que esta possui, pois, conforme alerta Cassirer, a arte

não é nem uma imitação de coisas físicas, nem um simples transbordar de sentimentos poderosos. É uma interpretação da realidade - não através de conceitos, mas de intuições; por meio não do pensamento, mas das formas sensuais (CASSIRER, 1994, p. 240).

No campo musical essa afirmativa encontra a subjetividade presente em quem faz música e também no seu ouvinte. Ao passo que uma coletividade expressa um modo próprio de fazer e/ou apreciar a produção musical, ganha-se evidência o aspecto cultural da música, que é onde as subjetividades encontram suas similitudes.

A música, entendida como "o som culturalmente organizado pelo homem" (Blacking, 1973 apud PINTO, 2001, p. 224), manifesta-se na paisagem sonora e nela encontra as bases sonoras para seu surgimento e perpetuação. Cassirer, após discorrer sobre a função mimética da arte, afirma que a música é uma imagem de coisas. Ao citar Aristóteles, para quem a imitação era mais do que a verdadeira natureza, pois comporta a espontaneidade do artista, Cassirer explica que

até o tocar flauta ou dançar não passa de uma imitação, pois o flautista ou o dançarino representam com seus 
TORRES, M. A.; KOZEL, S. Paisagens sonoras: possíveis caminhos aos estudos...

ritmos o caráter dos homens, bem como o que eles fazem e sofrem (CASSIRER, 1994, p. 227-228).

A cultura, a paisagem e o lugar concedem as bases para a construção musical, que em diferentes contextos assimilou os sons presentes no espaço, chegando, em certos casos, a alterar a forma de pensar e fazer música, conforme aponta Claire Gui:

As primeiras composições da música descritiva, no século XIX, a integração do 'ruído' nas composições musicais, a partir dos anos 1920, e então a procura de uma estética do ouvir a paisagem sonora e a criação de músicas espaciais na década de 1960 (por John Cage, Pierre Schaffer e Murray Schafer) contribuiu para várias transformações no fazer musical, porque o espaço, o ambiente e o território se tornaram elementos inerentes no processo de compor música ${ }^{4}$ (GUI, 2007, p. 3).

A música retrata a cultura e a memória do povo. É uma coleção de sons concebidos e produzidos por sucessivas operações de pessoas que ouvem bem (SCHAFER, 1991, p. 187), que quando executada, integra-se à paisagem sonora tornando-se um de seus elementos. Ao referir-se ao trabalho do antropólogo Alan P. Merrian ${ }^{5}$, Pinto afirma que "o fazer musical é um comportamento aprendido, através do qual sons são organizados, possibilitando uma forma simbólica de comunicação na inter-relação entre indivíduo e grupo". (PINTO, 2001, p. 224). Compreende-se, portanto, que a música é um elemento cultural, assim como é um elemento integrante da paisagem sonora, e é por ela transformada. Os sons presentes na paisagem sonora, sejam eles de origem natural ou produzidos pelos seres humanos nas mais variadas formas, estão inteiramente ligados à memória e à cultura.

O estudo da cultura e da paisagem pautado na paisagem sonora, possível por meio de uma abordagem geográfica humanista-cultural, traz à luz as preocupações com a compreensão de como o indivíduo e o coletivo constroem e concebem o espaço. A paisagem sonora é, dessa forma, apreendida e ao mesmo tempo transformada, diferentemente em cada localidade, em cada grupo, em cada cultura.

\section{MÚSICA DA/NA PAISAGEM SONORA: ELEMENTOS DA PAISAGEM, ELEMENTOS CULTURAIS}

A identidade baseia-se nos valores construídos durante a vida de um indivíduo, no contato com diferentes pessoas em diferentes lugares, somados aos valores acerca dos lugares onde viveu e do lugar onde vive. As experiências afetam a percepção acerca dos lugares. Carney, ao discorrer sobre as experiências de vida das pessoas, afirma que: Nosso lugar de nascimento deixa uma marca que de-
termina a maneira como percebemos outros lugares. A
música contribui para recordações de experiências do
lugar doméstico, tais como tocar música com parentes
em uma reunião de família, entoar cânticos de Natal
durante as Festas ou praticar um instrumento, como as
lições de piano recebidas quando criança. (CARNEY,
2007, p. 132)

A música de um lugar pode oferecer ao estudo geográfico elementos para a leitura do compartilhamento e da construção da memória e dos símbolos nele existentes, visto que ela, segundo Carney (2007, p. 145), tanto reflete quanto influencia as imagens que as pessoas possuem de lugares e a forma como essas imagens mudaram significativamente as atitudes das pessoas para com esses lugares. Para este autor "esse é outro passo para se compreender a 'geografia da mente"'. Carney ainda afirma que:

No estudo da música como um meio, devem ser levados em consideração o mensageiro e o mecanismo desse meio, isto é, os compositores, arranjadores, músicos, instrumentos, engenheiros de som, equipamento de gravação e estúdios de gravação. Por exemplo, os antecedentes culturais do compositor, suas percepções e conhecimento do lugar, bem como suas intenções (propósito, fundamentação lógica, objetivos, inclusão ou exclusão de determinados aspectos do lugar e o público ouvinte), podem influenciar a natureza do lugar representado. (CARNEY, 2007, p.144).

O estudo da música deve levar em consideração o lugar onde ela é produzida e tocada, com seus valores sociais e culturais. Pensar o lugar remete a pensar na localização, assim como nas paisagens que este comporta. Cosgrove (2004, p. 99) especifica três implicações

4 Tradução livre.

5 A referência é ao livro The Anthropology of Music, publicado em 1964 pela Northwestern University Press, considerado decisivo para a abordagem antropológica nos estudos da etnomusicologia. 
TORRES, M. A.; KOZEL, S. Paisagens sonoras: possíveis caminhos aos estudos...

do conceito de paisagem:

(1) um foco nas formas visíveis de nosso mundo, sua composição e estrutura espacial; (2) unidade, coerência e ordem ou concepção racional do meio ambiente; (3) a idéia de intervenção humana e controle das forças que modelam e remodelam nosso mundo.

Acrescenta-se à ideia de Cosgrove o fato de que todas as formas presentes na paisagem devem ser levadas em consideração, tanto as visíveis, quanto as percebidas por meio dos outros sentidos humanos. A paisagem relaciona natureza e sociedade, ou o meio e o homem, ao passo que este toma consciência do esquema da natureza que o envolve.

Entendendo a paisagem como portadora de elementos visuais, sonoros, odoríferos e tácteis, e portadora também dos significados dados a esses elementos pelas pessoas que os vivenciam, o estudo da música ainda deve levar em consideração os demais constituintes da paisagem sonora do lugar, como elementos para se pensar nas primeiras bases sonoras fornecidas ao músico. Frédéric Roulier(1999) propôs uma "Geografia dos meios sonoros", trazendo à discussão o meio sonoro numa abordagem geográfica. Em seu artigo Por uma geografia dos meios sonoros ${ }^{6}$, Roulier faz uma reflexão acerca das informações contidas no espaço sonoro, e o analisa numa perspectiva temporal, relacionando ainda ao clima e ao relevo, os quais influenciam diretamente em determinadas paisagens sonoras. Neste estudo o autor propõe uma Geografia do ruído, que caminha para uma Geografia dos meios sonoros. Para tal estudo, fundamenta-se na Geografia social, a qual, segundo ele, interessa-se pelos produtos dos espaços (territórios, paisagens etc.), e pelas variações geográficas destes produtos de acordo com as escalas das análises e dos grupos sociais.

A Geografia do ruído está ligada aos estudos de quantidade e qualidade dos ruídos produzidos em diferentes lugares, e para isso Roulier cita o exemplo das taxas de exposição a mais de 65 DB (A) entre os países do norte e do sul da Europa. Para ele, a Geografia do ruído interessa-se primeiramente nos contextos e nos efeitos prejudiciais que os sons podem causar nas pessoas. Numa segunda instância, tem como objetivo estudar a variedade dos sons, que se ligam à subjetividade, mas que informam diferentes modos de vida e comportamentos de um povo. Justificando o uso do termo "meio sonoro", explica que é o todo do relacionamento material e abstrato entre algo e seu ambiente sonoro, constituindo-se num campo geográfico de estudo que apreende o mundo sonoro que integra a Geografia do ruído e dos ruídos. Numa pesquisa dos meios sonoros, o ruído e os ruídos da cidade são relacionados à sua morfologia, seu planejamento e sua arquitetura. Cada cidade, cada lugar tem sua identidade sonora, numa variação de sons entre um lugar e outro, e também entre os tempos e as culturas.

A identidade sonora de um lugar pode estar representada em uma música, quando esta apresenta os elementos da paisagem do mesmo. Para Kong, a música pode transmitir imagens do lugar, e também pode servir como fonte primária para compreender a natureza e a identidade dos lugares (KONG, 1995, p. 03). Carney (2007, p. 140-142), em seu trabalho sobre as músicas nos Estados Unidos, faz um levantamento das músicas que citam os elementos naturais de um lugar. Cita ainda o movimento dos músicos de uma região para outra, proporcionando assim o movimento de gêneros e subgêneros musicais de um lugar para outro nos Estados Unidos.

Cada lugar e cada contexto oferecem as bases para se pensar a música. Para Carney

As características únicas de lugares específicos podem oferecer as pré-condições necessárias a novas idéias musicais. O contexto histórico, ambiental e social de um lugar, muitas vezes, fornece cenário e inspiração para determinado indivíduo ou grupo criar música. (CARNEY, 2007, p.138).

A relação existente entre a música e o lugar sempre foi objeto de atenção dos músicos e dos envolvidos com essa arte, como os fabricantes de instrumentos e produtores musicais. Uma evidência para este fato é a forma e a sonoridade de cada instrumento musical. $\mathrm{Na}$ construção de um instrumento, sua sonoridade é pensada com base no lugar onde ele será tocado. Diante disso, os instrumentos acústicos possuem uma forma que possibilita uma propagação maior dos sons por eles produzidos, diferente de uma guitarra elétrica, que, quando tocada sem estar conectada a um amplificador, produz um som de baixo volume e intensidade. Caznok discorre acerca desse tema, ao afirmar:

Parece óbvio dizer que dimensão acústico-espacial sempre esteve enraizada na consciência de músicos e ouvintes desde o canto gregoriano até os dias de hoje, pela simples razão de não ser possível separar

6 Título original: Pour une géographie des milieux sonores. 
TORRES, M. A.; KOZEL, S. Paisagens sonoras: possíveis caminhos aos estudos...

o som de seu habitat acústico. No entanto, é somente a partir dessa obviedade que se podem acompanhar as transformações ocorridas nessa consciência, pois ela encerra em si os caminhos perceptivos priorizados e desenvolvidos pelo homem ocidental. (CAZNOK, 2003, p. 68).

A escolha dos timbres de cada instrumento também pode estar relacionada aos sons que as pessoas já estão habituadas a ouvir. Não é estranho para um brasileiro ouvir os sons das platinelas de um pandeiro, sons de chocalhos, ou mesmo o som agudo das cordas de um cavaquinho. Da mesma maneira, o toque de tambores - como congas, quintos e tumbadoras - não são estranhos para os povos africanos e os países que tem em sua formação étnica a presença da cultura africana.

O estudo geográfico através da música deve compreender sua localização, a cultura, as influências da paisagem sonora local, sonoro-musicais do passado local, e as influências sonoro-musicais externas. Segundo Kong, no contexto da análise musical deve-se haver uma preocupação tanto para o lugar simbólico da música na vida social, bem como para os simbolismos empregados na música. (KONG, 1995, p. 8).

Carney (2007, p. 130-131) em seu estudo, citou algumas taxonomias gerais ao referir-se às pesquisas geográficas em relação à música, e dentre elas destacamos:

- O efeito da música na paisagem cultural;

- As relações da música com outros traços culturais em um contexto de lugar;

- A relação da música com o meio ambiente;

- O lugar de origem (berço cultural) e a difusão de fenômenos musicais para outros lugares;

- Os elementos psicológicos e simbólicos da música relevantes na modelagem do caráter de um lugar, isto é, na imagem, no sentido e na consciência deste.

Para desvelar as relações existentes entre a música e a paisagem cultural, pode-se fazer uso de vários aportes metodológicos, como entrevistas, mapas mentais e análises de discursos. A paisagem sonora e a cultura local podem ser identificadas em análises de trechos de músicas levantadas em entrevistas, que servirão como subsídios para uma leitura das representações acerca do lugar estudado, e da dimensão que o elemento sonoro toma no contexto desse espaço pelos seus moradores. Parte dessa proposta foi colocada em prática em recente trabalho desenvolvido por
Torres (2009), ao analisar a paisagem sonora da Ilha dos Valadares, no Paraná, com base nas percepções e memórias de tocadores de fandango que nela vivem, revelando que a paisagem sonora possui características da paisagem vivida, que evoca a memória, re-significa o lugar, e faz da llha dos Valadares um lugar familiar para os entrevistados.

O lugar comporta objetos e valores através dos símbolos, signos e significados. É no lugar que as relações sociais ocorrem, e através delas os valores são compartilhados. A topofilia está ligada a estes valores quando surge no indivíduo a sensação de pertencimento ao lugar. Com o compartilhamento dos valores e das memórias, temos então a possibilidade das análises acerca da identidade de cada indivíduo e do grupo. Assim, têm-se a possibilidade de análise dos três eixos da Geografia cultural, conforme citados por Claval (1997, p. 93): partindo das sensações e das percepções; através da ótica da comunicação, compreendida como uma criação coletiva; e apreendida na perspectiva da construção de identidades.

\section{PELA CONTINUIDADE DOS ESTUDOS DOS SONS: ALGUMAS CONSIDERAÇÕES}

O presente artigo buscou apontar caminhos aos geógrafos que se interessam pela questão da paisagem sonora. Para isso, inicialmente discutiu o conceito de paisagem na Geografia, para em seguida adentrar às questões concernentes à paisagem sonora.

A paisagem sonora compreendida como os sons de um ambiente (SCHAFER, 2001), deve considerar também a música tocada e ouvida nos diferentes lugares. Entendida como um evento (ONG apud POCOCK, 1989, p. 193), deve ser analisada dentro de um recorte de tempo maior que o destinado à paisagem visual, e está totalmente atrelada à memória. A música, dessa forma, integra a paisagem sonora, e é ainda um registro dos sons de uma época (SCHAFER, 2001, p.151).

O CD "O som e o sint: uma trilha para o som e o sentido", produzido por Hélio Zizkind, que integra o livro "O som e o sentido" de José Miguel Wisnik (1989), aponta para as influências da paisagem sonora na música, e relaciona os ritmos do trabalho aos ritmos musicais de diferentes culturas. Halbwachs chama a atenção para a criação do ritmo no seu livro "A memória coletiva" ao afirmar que o ritmo musical é uma construção social:

Ele não existe na natureza? Não imaginamos que um homem isolado possa descobrir sozinho no espaço sonoro essas divisões rítmicas? Se algum fenômeno natural insinuasse o ritmo não haveria necessidade de 
TORRES, M. A.; KOZEL, S. Paisagens sonoras: possíveis caminhos aos estudos...

recebê-lo dos outros homens. Os ruídos que nos chegam da natureza, e só dela, não se sucedem segundo uma medida ou uma cadência qualquer. O ritmo é um produto da vida em sociedade. Sozinho, o indivíduo não poderia inventá-lo. (HALBWACHS, 2006, p. 207).

Wisnik (1989, p. 33) afirma ainda que a música organiza sons que o mundo oferece, e para Blackin, a música é entendida como o som culturalmente organizado pelo homem ( BLACKIN apud PINTO, 2001, p. 224). Segundo Levintin,

[...] o estudo da música tem uma importância central para a ciência cognitiva porque a música está entre as atividades humanas mais complexas, envolvendo percepção, memória, tempo, agrupamento de objetos, atenção e (no caso da performance) perícia e uma coordenação complexa da atividade motora (LEVINTIN, 2006, p. 44).

Desse modo, a música apresenta-se como importante elemento a ser considerado no levantamento das percepções e memórias de cada indivíduo. Dessa forma, os estudos com base na paisagem sonora apresentam-se pertinentes à Geografia, por meio de uma abordagem Humanista-Cultural, pois possibilitam adentrar o universo simbólico de cada indivíduo, o que contribui para a compreensão da cultura e do lugar.

\section{REFERÊNCIAS}

ALMEIDA, Maria Geralda de. Em busca do poético do sertão. In: ALMEIDA, M. G. de; RATTS, A. (Orgs.). Geografia: leituras culturais. Goiânia: Editora Alternativa, 2003.

APROBATO FILHO, Nelson. Kaleidosfone: as novas camadas sonoras da cidade de São Paulo. Fins do século XIX - início do XX. São Paulo: Editora da Universidade de São Paulo: Fapesp, 2008.

BERQUE, Augustin. Paisagem-marca, Paisagem-matriz: elementos da problemática para uma Geografia Cultural. In: CORREAA, R. L.; ROZENDAHL, Z. (Orgs.). Paisagens, textos e identidade. Rio de Janeiro: EDUERJ, 2004.

CARNEY, George. O. Música e lugar. In: CORREAA, R. L.; ROSENDAHL, Z. (Orgs.). Literatura, música e espaço. Rio de Janeiro: EDUERJ, 2007.

CASSIRER, Ernst. Ensaio sobre o homem: introdução a uma filosofia da cultura humana. São Paulo: Martins Fontes, 1994.

. A filosofia das formas simbólicas: I - A Linguagem. São Paulo: Martins Fontes, 2001.
CAZNOK, Yara B. Música: entre o audível e o visível. São Paulo: Editora da UNESP, 2003.

CLAVAL, Paul. As abordagens da Geografia Cultural. In: CASTRO, I. E.; GOMES, P. C. da C.; CORREAA, R. L. (Orgs.). Explorações geográficas: percursos no fim do século. Rio de Janeiro: Bertrand Brasil, 1997.

A paisagem dos geógrafos. In: CORRÊA, R. L.. ROZENDAHL, Z. (Orgs.). Paisagens, textos e identidade. Rio de Janeiro: EDUERJ, 2004.

COSGROVE, Denis. A Geografia está em toda parte: cultura e simbolismo nas paisagens humanas. In: CORREAA, R. L.; ROSENDAHL, Z. (Orgs.). Paisagem, tempo e cultura. Rio de Janeiro: EDUERJ, 2004.

GASPAR, Jorge. O retorno da paisagem à Geografia: apontamentos místicos. Finisterra - Revista Portuguesa de Geografia, XXXVI, 72, p. 83-99, 2001.

GUI, Claire. Espaces sonores, lieux et territoires musicaux: les géographes à l'écoute. Cafés Géographiques. n 1191, 16/11/2007. Disponível em: <http://www.cafe-geo.net/article. php3?id_article=1191>. Acesso em: 21/05/2008.

HALBWACHS, Maurice. A memória coletiva. São Paulo: Centauro, 2006.

KONG, Lily. Popular music in geographical analyses. Progress in Human Geography, v. 19, p. 183-198, 1995.

LEVITIN, David. Em busca da mente musical. In: ILARI, B. S. (Org.). Em busca da mente musical: ensaios sobre os processos cognitivos em música - da percepção à produção. Curitiba: Ed. da UFPR, 2006.

PINTO, Tiago de O. Som e música. Questões de uma antropologia sonora. Revista de Antropologia, São Paulo, v. 44, n. 1, p. 222-226, 2001.

POCOCK, Douglas. Sound and the Geographer. Journal of the Geographical Association, v.74, n.324, Part 3, June 1989.

ROULIER, Frédéric. Pour une géographie des milieux sonores. Cybergeo, Environment, Nature, Landscape, Article 71, 1999. Disponível em: <http://www.cybergeo.eu/index5034.html> Acesso em: 28/04/2005.

SALGUEIRO, Teresa B. Paisagem e Geografia. Finisterra - Revista Portuguesa de Geografia, XXXVI, 72, p. 37-53, 2001.

SCHAFER, R. Murray. A afinação do mundo: uma exploração pioneira pela história passada e pelo atual estado do mais negligenciado aspecto do nosso ambiente: a paisagem sonora. São Paulo: Editora da UNESP, 2001.

. O ouvido pensante. São Paulo: Fundação Editora da UNESP, 1991.

TORRES, Marcos A. A paisagem sonora da llha dos Valadares: percepção e memória na construção do espaço. 152 f. Dissertação (Mestrado em Geografia) - Programa de Pós- 
TORRES, M. A.; KOZEL, S. Paisagens sonoras: possíveis caminhos aos estudos...

Graduação em Geografia, Universidade Federal do Paraná, Curitiba, 2009.

TUAN, Yi-fu. Topofilia: um estudo da percepção, atitudes e valores do meio ambiente. São Paulo: Difusão Editorial, 1980.

WATERMAN, Stanley. Geography and music: some introductory remarks. GeoJournal, Springer Netherlands, v.65, fev. 2006.

WISNIK, José M. O som e o sentido. São Paulo: Companhia das Letras, 1989. 